Ensino, Saúde e Ambiente - V5 (1), pp. 1-11, abril. 2012

\title{
EDUCAÇÃO AMBIENTAL: DA (DES) CONSTRUÇÃO DE UM CLICHÊ A UMA PERSPECTIVA CRÍTICA EM EDUCAÇÃO.
}

\section{ENVIRONMENTAL EDUCATION: THE (DE) CONSTRUCTION OF A CLICHÉ TO A CRITICAL PERSPECTIVE ON EDUCATION.}

\author{
Priscila Cardoso Moraes de Souza \\ Instituto Federal de Educação, Ciência e Tecnologia do Rio de Janeiro - IFRJ \\ Programa de Pós-Graduação Stricto Sensu em Ensino de Ciências \\ Mestrado Profissional em Ensino de Ciências \\ priscila.moraes@ifrj.edu.br
}

\section{Resumo}

A presente comunicação tem por objetivo propor reflexões a respeito da urgente necessidade de superação da visão reducionista da Educação Ambiental (EA) no cenário atual, que a torna, muitas vezes, um mero clichê, como tantos outros modismos temáticos presentes no contexto educacional, sendo traduzida em práticas educativas simplistas, impossibilitando, assim, o debate acerca dos aspectos sociais, políticos e econômicos que a constituem. Propõe-se a problematização da temática ambiental por meio do questionamento das ênfases e omissões em alguns documentos oficiais que dela tratam, direta ou indiretamente. São apontadas fragilidades e desafios, e enfatiza-se a importância de que a Educação Ambiental seja trabalhada de modo crítico e significativo em nossas escolas.

Palavras-chave: educação ambiental crítica - consumo - reciclagem - educação

\begin{abstract}
This Communication aims to propose reflections on the urgent need to overcome the limited vision of environmental education (EE) in the current scenario, which makes it often a mere cliche, like many other fashion themed gifts in the educational context, being translated into educational practices simplistic, thus disabling the debate about the social, political and economic factors that constitute it. It is proposed to questioning the environmental issue by questioning the emphases and omissions in some official documents that deal with it directly or indirectly. Are pointed out weaknesses and challenges, and emphasizes the importance of environmental education is crafted in a critical and significant in our schools.
\end{abstract}

Key words: environmental education critical - consumption - recycling - education 


\section{A Educação Ambiental que temos}

O discurso da necessidade urgente de inserção da temática ambiental nos currículos escolares e no próprio cotidiano escolar não é novo. Seja por meio de legislações específicas sobre o tema ou por movimentos educacionais da área, o fato é que a presença da Educação Ambiental (EA) no contexto educacional é o que podemos chamar, sem receio, de consensual, tendo em vista a importância das questões ambientais no cenário social em que vivemos. Entretanto, pouco se discute o modo pelo qual a EA deve ser trabalhada na escola, importando apenas que, de algum modo, esteja "lá".

Assim, enquanto educadores, incorremos no sério risco, sempre presente no cenário educacional, de nos colocarmos à frente de mais um modismo temático, dentre muitos outros presentes nas agendas escolares. Se por um lado percebemos que a formação docente para tratar da EA é insuficiente; por outro, verificamos que sua abordagem numa perspectiva mais crítica é muitas vezes negligenciada, seja pela falta de informação/formação do professor, ou mesmo por "mazelas" educacionais, tão presentes em nossas escolas, nas quais se busca dar conta dos conteúdos, mas pouco se faz em relação ao questionamento sobre as ênfases e omissões dos mesmos.

Vale destacar que o tema meio ambiente foi inserido mais especificamente na educação a partir de sua orientação como tema transversal nos Parâmetros Curriculares Nacionais - PCN, em 1997, e, como tal, deve perpassar por todas as disciplinas e/ou áreas do conhecimento. Entretanto, essa perspectiva da transversalidade pouco é evidenciada em nossas escolas. Ao contrário, muitas vezes, o tema meio ambiente é visto como atribuição dos professores de Ciências, em um movimento de fragmentação do conhecimento, que reflete a fragmentação da própria realidade.

Somado a isso, temos a constatação de que, de modo geral, a EA é tratada de modo temático, isto é, trabalhada em uma perspectiva folclórica do verde e da natureza, com enfoque preservacionista, que muitas vezes impõe exclusivamente aos sujeitos a culpa pela degradação ambiental. Nessa perspectiva folclórica, estes mesmos sujeitos são "convidados" a, individualmente, reverterem a situação atual, por meio da mudança do seu comportamento, como forma do que Brügger (1994) denominou de "adestramento ambiental", a partir do qual se busca exclusivamente a mudança de comportamento individual em detrimento da mudança refletida de valores sociais.

Cabe dizer que o discurso do "faça a sua parte" não é novo e traduz a emergência 
e complexidade dos problemas ambientais, enfatizando, também, uma dimensão individualizada em relação à EA, centrada na parte, no comportamento, em detrimento de uma consciência coletiva, baseada no entendimento de que a ação comum e conjunta dos indivíduos rumo à consciência ambiental é mais significativa do que a ação individual e independente (GUIMARÃES, 2004; 2006).

\section{Que Educação Ambiental se faz nas escolas?}

Reforçando a afirmativa inicial de que a EA vem sendo tratada nos espaços escolares em uma perspectiva temática não problematizada, no relatório "Um Retrato da Presença da Educação Ambiental no Ensino Fundamental Brasileiro: o percurso de um processo acelerado de expansão", Veiga (2005) considera que a inserção da EA nas escolas entre os anos de 2001 a 2004 foi realmente acelerada e crescente. Nesse sentido, verifica-se que o problema, na verdade, não é a disseminação do tema, mas sim a forma como é entendido no cenário educacional. Guimarães (2004, p. 27) considera que essa inserção constitui-se em "uma resposta às expectativas que a sociedade projeta sobre a escola (...)", refletindo uma demanda da própria sociedade.

A busca pelo atendimento dessa demanda gera, muitas vezes, uma abordagem simplista da EA, negligenciando o debate e a problematização necessários à compreensão de seus aspectos mais significativos.

Subsidiando nossa afirmação, Loureiro et al (2006), em relevante pesquisa nacional, editada e divulgada pelo MEC/UNESCO com título "O que fazem as escolas que dizem que fazem educação ambiental"?, apresenta a situação da Educação Ambiental nas escolas brasileiras, quanto aos conteúdos, a gestão e a percepção da Educação Ambiental nas escolas, tendo como objetivo "mensurar" a abrangência da EA nos espaços educativos nacionais, de modo a desvendar quais os incentivos, prioridades, enfoques e resultados obtidos em relação ao tema em âmbito nacional.

De modo geral, pode-se dizer que os dados coletados e analisados na referida pesquisa apresentaram uma situação que, embora considere os grandes avanços na inserção da temática ambiental nas escolas, considera que nesse aparente progresso encontra-se também a maior constatação e o maior desafio: verificou-se que os objetivos principais da Educação Ambiental nas escolas são os de conscientizar alunos e

1 Relatório publicado em 2005 pelo Instituto Nacional de Pesquisa e Estudos Educacionais Anísio Teixeira - INEP. 
comunidades para a "plena cidadania" e sensibilizar para o convívio com a natureza. Estas ações são na maioria das vezes, pautadas, exclusivamente; na solução de problemas locais, principalmente no que tange à coleta seletiva de lixo e aos processos de reciclagem, configurando-se numa visão simplista e reducionista da Educação ambiental, que é traduzida nas práticas escolares vigentes:

(...) mais uma vez se verifica a necessidade de alterar o quadro sobre as percepções do que se coloca como objetivos da Educação Ambiental, incluindo elementos para além da prática discursiva da sensibilização ou conscientização. Limitar os fins da Educação Ambiental à sensibilização do convívio com a natureza e à conscientização para a cidadania plena permite identificar um conceito estreito dessa Educação (LOUREIRO, 2006, p.45).

Essa constatação, a nosso ver, configura-se como o maior desafio que se coloca à EA: Como transcender do clichê Educação Ambiental, superando o lugar comum, para atingir uma esfera emancipatória e crítica das especificidades da questão ambiental? Guimarães (2004, p.42) considera, que a dificuldade dos professores em superar uma proposta de educação conservadora, "mesmo quando sensibilizados e motivados a inserir a dimensão ambiental em suas práticas educativas," constitui-se em uma fragilidade da EA em nossas escolas mas, ao mesmo tempo, nos inquieta a traçar caminhos que efetivem mudanças nesse quadro. Ou seja, a dificuldade de ruptura com as práticas conservadoras, serve-nos de estímulo, para que novas ações, caminhos e estratégias sejam propostos.

\section{O que há de ambiental nos documentos “oficiais” que norteiam a educação?}

Em estudo recente, Bomfim (2010) buscou aproximar a Legislação Ambiental (LA) do Educador da Educação Básica, de modo que servisse como referência inicial à temática ambiental e orientasse uma Educação Ambiental Crítica, na perspectiva de "uma EA não circunscrita às questões comportamentais e individualizantes no trato da degradação e preservação da natureza" (p.01).

Dentre essas leis, destacamos a Lei 9.795, que instituiu em 27 de abril de 1999 a Política Nacional de Educação Ambiental (PNEA), indicando, em seu artigo $9^{\circ}$, que a EA deve ser ministrada em todos os níveis escolares do ensino formal, possibilitando "o desenvolvimento de uma compreensão integrada do meio ambiente em suas múltiplas e complexas relações, envolvendo aspectos ecológicos, psicológicos, legais, políticos, sociais, econômicos, científicos, culturais e éticos”. (BRASIL, 1999). Essa afirmação 
apresenta o enfoque dado à Educação ambiental no discurso governamental que, embora trate de aspectos "econômicos e éticos", dentre outros, pouco se observa no contexto da Lei, em suas ênfases e omissões, da questão da diminuição do consumo, do consumo consciente e muito menos sobre a reflexão da descartabilidade e obsolescência dos produtos no cenário atual, como se essas questões não possuíssem relação com a evidente degradação e com a escassez de recursos naturais.

Em outro momento, defende que as ações de estudos, pesquisas e experimentações devem promover a difusão de conhecimentos sobre a questão ambiental. Entretanto, não suscita os questionamentos necessários para que a complexidade da questão ambiental venha à tona, o que faz perceber uma compreensão já esvaziada de seus princípios. Vale lembrar que, quando falamos nesses princípios, não buscamos padronizar ou rotular o que contempla ou não a EA, mas, sobretudo ressaltar que existem sim, princípios básicos dessa dimensão educacional e política que não podem ser esquecidos ou ocultados, seja na esfera escolar ou na vida cotidiana da sociedade. Castro (2009, p.173) defende que "a EA implica em uma tomada de consciência de uma complexa rede de fatores políticos, econômicos, culturais e científicos".

Em trabalho recente, nesse enfoque, Souza e Trajano (2010), chamaram a atenção para o fato de que na Lei de Diretrizes e Bases da Educação Nacional, de 1996 e em suas pequenas alterações em anos posteriores, pode-se notar a ausência da abordagem em educação ambiental, ainda que se trate indiretamente, no que se refere à abrangência do "mundo físico e natural" como consta no $\S 1^{\circ}$ do Art. 26. Entretanto o enfoque dado não se relaciona necessariamente à EA, muito menos de forma crítica. Isto é, exigir que o currículo escolar contemple "o conhecimento do mundo físico e natural", não significa garantir que os alunos construam uma consciência crítica, e, portanto, não mais ingênua, da Educação Ambiental, compreendendo a linguagem da natureza e, sobretudo compreendendo os processos sociais, políticos, culturais e econômicos pelos quais a atual situação de degradação foi sendo, ao longo dos anos, ocasionada.

Afirmam, ainda, que essa lacuna na Lei de Diretrizes e Bases da Educação Nacional - LDB, reflete uma lacuna existente, de modo geral, na própria sociedade e na sua relação com o meio ambiente, oriunda de uma construção cartesiana na qual os indivíduos se percebem separados, alheios à natureza. Vale dizer que o comportamento antropocêntrico da sociedade é fruto justamente da dicotomia homem-natureza, o que 
impede que o próprio homem se aperceba "das relações de interdependência entre os elementos existentes no meio ambiente" (GUIMARÃES, 1995, p.12).

Na mesma esfera oficial são lançados em 1997, os Parâmetros Curriculares Nacionais - PCN, buscando disseminar a Educação Ambiental como tema transversal do eixo meio ambiente, sem caracterizar-se como uma disciplina específica, perpassando pelos diferentes níveis de ensino.

O documento apresenta uma abordagem teórica abrangente no que diz respeito aos principais temas que envolvem a $\mathrm{EA}$, e que são comuns em documentos que busquem dela tratar, o que não significa que haja a criticidade necessária para que abordagem ambiental supere a dimensão temática para atingir a dimensão de uma consciência ambiental que não se restrinja à participação individual sob uma ótica pragmática de mudança comportamental.

Por outro lado, Bomfim (2010, p. 15) coloca que, contraditoriamente, os PCN fizeram os temas ambientais estarem mais presentes nas escolas, embora sua implementação tenha ocorrido em um "período marcado por políticas educacionais de teor neoliberal". No entanto, a maior presença da temática ambiental nas escolas evidencia, também, que a abordagem da reciclagem como solução para os problemas ambientais tem sido priorizada nos projetos educacionais em detrimento de um debate sobre os aspectos políticos, econômicos e sociais engendrados pela EA, em uma perspectiva crítica.

\section{A falsidade da reciclagem como solução para os problemas ambientais}

No contexto de degradação e evidente escassez dos recursos naturais surgem os processos de reciclagem como solução, já que, por meio de diferentes processos químicos e tecnológicos, esse mecanismo transmite a idéia da renovação dos recursos. Não negamos essa importância, mas ao mesmo tempo questionamos: a quem ela atende? Layrargues (2008, p.211), defende que:

"O verdadeiro consumidor verde, ou melhor, o verdadeiro cidadão consciente e responsável não é aquele que escolhe consumir preferencialmente produtos recicláveis, ou que se engaja voluntariamente nos programas de reciclagem, mas aquele que cobra do Poder Público, por meio de processos coletivos de pressão, que o mercado ponha um fim na obsolescência planejada e na descartabilidade, e, sobretudo, que exige do Estado a implementação de políticas públicas que destruam os mecanismos perversos de concentração de renda (...)." 
No momento em que se dissemina a reciclagem como solução para os problemas ambientais, dissemina-se, também, a idéia de que não é necessário diminuir o consumo ou ao menos refletir sobre ele. Nesse sentido, nos apropriamos da afirmação de Zaneti:

“(...) para reduzir o impacto no meio ambiente, tanto na acumulação do lixo, como no esgotamento das fontes de recursos naturais, começam os processos de reciclagem. Mas de nada adiantam campanhas para reciclar e programas de Coleta Seletiva de Lixo, se não fizermos um trabalho de internalização de novos hábitos e de atitudes para que, num futuro próximo, não haja mais lixo excessivo e a sua causa, o consumo desmedido, tenha sido controlada" (ZANETI apud LAYRARGUES, 2008, p. 214).

Nessa perspectiva, justamente pela gravidade da questão do lixo é que este tema vem sendo centralizado pelo movimento ambientalista e também por nossas escolas como principal tema dos projetos de educação ambiental, como se a EA em si fosse reduzida à questão da reciclagem.

A denominada Política ou Pedagogia dos 3R's: Reduzir, Reutilizar e Reciclar. Embora haja a presença do imperativo "reduzir", na prática, pouco se tem feito para se reduzir efetivamente o consumo, até pelo fato de não ser este o interesse dos grupos dominantes. Sobre essa questão, Layrargues (2008, p.180) afirma que "a despeito dessa tendência pragmática, pouco esforço tem sido dedicado à análise do significado ideológico da reciclagem".

Outra questão que chama ainda mais atenção diz respeito à lucratividade adquirida com a reciclagem que, num movimento contraditório, gera recursos bilionários a cada ano para as grandes empresas que gerenciam os processos e não para o catador, que recolhe e inicia a separação do lixo, o que significa que os ganhos com a reciclagem estão evidentemente mal distribuídos (Ibid, 2008), cabendo o questionamento: a quem atende a reciclagem?

Nesse contexto, não é de surpreender que o discurso governamental represente a ideologia hegemônica encarregada de manter os valores culturais instituídos na sociedade, (LAYRARGUES, 2008) incluindo aqui a lógica do consumo desnecessário e desenfreado, que obviamente acarretará um esgotamento dos recursos naturais.

Vale destacar que a crise ambiental em suas nuances mais graves, manifesta-se pela escassez de recursos não renováveis, pela destruição dos ecossistemas vegetais nativos e oceânicos, empobrecimento acelerado da biodiversidade, radical transformação dos ecossistemas nativos ou a sua substituição por ecossistemas antrópicos gerados pela construção civil, poluição do ar e da água e, sobretudo a alterações de ordem climática mundial (SOFFIATI, 2008). O autor considera ainda que a crise ambiental é antes de 
tudo uma crise antrópica, derivada de atividades humanas, quer praticadas no modo de vida capitalista, quer no modo de vida do chamado socialismo, (ibidem, p.44) demonstrando mais uma vez que o problema não é novo.

\section{Desafios para a desconstrução de um clichê}

Ao observarmos as interfaces e as múltiplas dimensões da EA podemos afirmar que a desconstrução de seu significado como um mero clichê temático não é tarefa fácil, tendo em vista que, em uma perspectiva crítica e emancipada, sua missão é de denunciar não somente as mazelas engendradas pelo sistema do capital, como suas formas de camuflá-las, de denunciar as falsas ou paliativas políticas públicas ou mesmo as inúmeras propostas de ação em nome de um "desenvolvimento sustentável” (BOMFIM, 2008, p.13). Esse modelo de desenvolvimento, cujo discurso atende ao próprio capitalismo, assume claramente propostas neoliberais (Layrargues, 1997).

Em contraposição a essa perspectiva, o autor traça aspectos referentes ao ecodesenvolvimento, definindo-o como:

\footnotetext{
"Uma abordagem que entende que a satisfação das necessidades das gerações futuras deve ser garantida, isto é, deve haver uma solidariedade diacrônica sem que no entanto, comprometa a solidariedade sincrônica com a geração presente, já por demais sacrificada pelas disparidades sociais da atualidade (LAYRARGUES, 1997, p.5).
}

Layrargues (1997) sugere, portanto, que implementemos voluntariamente a estratégia de um teto do consumo material, isto é, limitar o consumo a partir de uma prudência ecológica e justiça social que nos permitam encontrar, no que chamou de esferas não-materiais da nossa vida, alguma gratificação. Caso contrário, permitiremos que o nosso cotidiano seja norteado pelo apelo do consumo e pela corrida pela aquisição e acumulação de bens, num contexto social no qual os indivíduos passam a ser valorizados pelo que possuem e não pelo que são enquanto sujeitos.

Löwy (2005, p.29) citando Marx, afirma que a produção capitalista acumula, por um lado, a força motriz histórica da sociedade, mas perturba, por outro lado, o metabolismo entre homem e terra, configurando de modo claro a relação entre os modos de produção capitalistas e a situação alarmante de degradação ambiental. A produção capitalista só desenvolve a técnica e a combinação do processo e produção social ao minar simultaneamente as fontes de toda riqueza: a terra e o trabalhador. Por mais 
radical que a afirmativa pareça ser não é difícil observar que os sintomas dessa exploração são evidentes.

Nesse contexto, a educação tem como desafio ser um dos mais importantes agentes de mudanças desejáveis na sociedade, acoplando-se a ela várias dimensões educativas, como a Educação Ambiental, que, por sua natureza abrangente e integradora, permeia várias áreas e, ao mesmo tempo, causa grandes impactos quando não consegue alcançar o objetivo de suscitar o desenvolvimento da consciência crítica, pela sociedade, em relação à problemática ambiental, em seus aspectos socioculturais, econômicos, políticos, científicos, tecnológicos, ecológicos e éticos, aos quais nos referimos.

Partindo de uma das marcantes afirmativas de Marx, de que o próprio educador deve ser educado, (MARX, apud BOMFIM, 2008, p.14.), apresenta que o educador, dentro de uma lógica mais crítica, sinta a necessidade de revisar sua prática, sua metodologia e principalmente as ênfases e omissões dos conteúdos trabalhados, tendo em vista que a educação ambiental é ideológica, isenta de neutralidade, trazendo consigo valores e concepções dentro do contexto sócio-histórico.

Assim (BOMFIM, 2008, p.14) afirma que

“(...) uma EA crítica é aquela que percebe a inevitabilidade do confronto político, porque assim como acontece com a relação capital e trabalho, a questão ambiental liga-se a conflitos de interesses, característica de uma sociedade desigual."

Apoiados em Guimarães et al (2009), defendemos que, mesmo em grupo minoritário, os professores devem tentar inserir uma perspectiva crítica em EA nas escolas através do embate hegemônico em práticas diferenciadas, assumindo uma postura crítica em seu fazer pedagógico, construindo novas lógicas, suscitando questionamentos sobre os aspectos sociais e políticos inerentes à Educação Ambiental, tendo como principal desafio o enfrentamento das questões que são omitidas nos próprios documentos "oficiais" que buscam nortear a educação, dos quais falamos anteriormente.

Há de se romper também com a prática restrita e superficial pela qual a maioria das escolas concentra-se essencialmente na metodologia da resolução de problemas ambientais locais como a questão do lixo e da reciclagem, muitas vezes sem a problematização necessária sobre os aspectos sociais, políticos e econômicos que envolvem a questão. 


\section{Considerações finais}

Com a breve análise que aqui tecemos sobre os aspectos que permeiam a educação ambiental no contexto atual, buscamos possibilitar, uma vez mais, a reflexão a respeito da inserção do tema EA nas escolas e também na vida social dos indivíduos, chamando atenção para o problema de se reduzir a Educação Ambiental, apenas, a prática da coleta seletiva de lixo e à reciclagem. Não obstante, buscamos repensar qual Educação Ambiental está sendo desenvolvida pelas escolas, por meio das políticas públicas que visam implementá-la.

Há, portanto, a urgência de mudanças sobre as percepções a respeito da EA, no intuito de que seu significado, em uma perspectiva crítica, seja efetivamente ampliado, não mais limitado ao enfoque reducionista da sensibilização ou conscientização no convívio com o meio natural, porque, de fato, "a EA não é sinônimo de 'Educação Ecológica" (grifo nosso), porque vai além do aprendizado sobre a estrutura e o funcionamento dos sistemas ecológicos, e abrange também a compreensão da estrutura e do funcionamento dos sistemas sociais" (LAYRARGUES, 2009, p.26). Há de se atingir, sobretudo, o objetivo de situar, ao longo da história, a questão socioambiental, em suas interfaces.

\section{Referências}

BRASIL. Lei n.9.795, de 27 de abril de 1999. Dispõe sobre a educação ambiental, institui a Política Nacional de Educação Ambiental e dá outras providências. Diário Oficial, Brasília,1999.

. Lei $n^{\circ}$ 9.394, de 20 de dezembro de 1996. Estabelece as Diretrizes e Bases da Educação Nacional. Diário Oficial da União. Brasília, no 248, 23/12/1996.

. Secretaria de Educação Fundamental. Parâmetros Curriculares Nacionais: Temas Transversais. Brasília: MEC/ SEF, 1997.

BOMFIM, A.M. Trabalho, Meio Ambiente e Educação: apontamentos à Educação Ambiental a partir da Filosofia da Práxis, In: XIV ENDIPE, 2008, Porto Alegre. XIV ENDIPE. Porto Alegre: EDIPUCRS, 2008. P. 1-14.

BOMFIM, A. M. Que fazer diante da Legislação Ambiental? (Desde o Código Florestal de 1965): alguns apontamentos aos Educadores. VI Simpósio Internacional sobre Trabalho e Educação. Anais CD-ROM. Faculdade de Educação - UFMG, 29-31 de agosto de 2011. ISSN: 1 807-5037 
BRÜGGER, P. Educação ou adestramento ambiental? Florianópolis: Letras Contemporâneas, 1994.

CASTRO. R. S. A construção de conceitos científicos em Educação Ambiental In: LOUREIRO. C. F. B.; LAYRARGUES. P. P.; CASTRO. R. S. (Orgs). Repensar a Educação Ambiental: Um olhar crítico. São Paulo: Cortez, 2009.

GUIMARÃES, M. et al. Educadores ambientais nas escolas: as redes como estratégia. Cad. CEDES, Abr 2009, vol.29, n.77, p.49-62. ISSN 0101-3262.

.A dimensão ambiental na educação. Coleção Magistério: Formação e Trabalho Pedagógico, São Paulo: Papirus, 1995.

.A formação de educadores ambientais. São Paulo: Papirus, 2004.

2006.

.Caminhos da Educação Ambiental: da forma à ação. São Paulo: Papirus,

LAYRARGUES, P.P. O Cinismo da Reciclagem: o significado ideológico da reciclagem da lata de alumínio e suas implicações para a educação ambiental. In: LOUREIRO. C.B.F. (org.). Educação Ambiental: Repensando o espaço da cidadania. Cortez, p. 185-222, 2008.

. Do ecodesenvolvimento ao desenvolvimento sustentável: evolução de um conceito? Revista Proposta, Rio de Janeiro, v.24, n.71, p.1-5, 1997.

Educação Ambiental com compromisso social: o desafio da superação das desigualdades. In: LOUREIRO. C. F. B.; LAYRARGUES. P. P.; CASTRO. R. S. (Orgs). Repensar a educação Ambiental: Um olhar crítico. São Paulo: Cortez, 2009.

LOUREIRO. C.B.F. et al. Conteúdos, Gestão e Percepção da Educação Ambiental nas Escolas. In: TRAJBER, R.; MENDONÇA. P.(Orgs.) O que fazem as escolas que dizem que fazem Educação Ambiental? Brasília: MEC, 2007.

LOWY, M. Ecologia e Socialismo. São Paulo: Cortez, 2005.

SOFFIATI, A. Fundamentos Filosóficos e Históricos para o Exercício da Ecocidadania e da Ecoeducação. In: LOUREIRO. C.B.F. (org.). Educação Ambiental: Repensando o espaço da cidadania. Cortez, p.27-72, 2008.

SOUZA, P.C.M. \& TRAJANO. S. As interfaces da Educação Ambiental na dimensão curricular: Uma análise documental. 2010 (Trabalho de conclusão de disciplina Stricto Sensu do PROPEC -Mestrado Profissional em Ensino de Ciências do Instituto Federal de Educação, Ciência e Tecnologia do Rio de Janeiro).

VEIGA, A. et al. Um retrato da presença da educação ambiental no Ensino Fundamental Brasileiro: o percurso de um processo acelerado de expansão. Brasília: Instituto Nacional de Estudos e Pesquisas Educacionais Anísio Teixeira, 2005. 